\title{
A combined experimental and analytical approach for the simulation of the sound transmission loss of multilayer glazing systems
}

\author{
Paolo Ruggeria*, Fabio Peron $^{\mathrm{a}}$,Nicola Granzotto ${ }^{\mathrm{b}}$, Paolo Bonfiglio ${ }^{\mathrm{c}}$ \\ ${ }^{a}$ Department of Design and Planning in Complex Environments, IUAV University of Venice \\ ${ }^{b}$ Department of Industrial Engineering, University of Padua \\ ${ }^{c}$ Engineering Department, University of Ferrara
}

\begin{abstract}
High sound insulation façade requirements in contemporary buildings, led to the development of high-performance multilayer glazing systems.

In this work a combined experimental and analytical approach has been adopted to predict the sound transmission loss of systems made of glass and PVB layers, which are used in several engineering areas (building, transportation, etc.).

In particular, the mechanical properties of glazing systems have been measured using resonance curve method of flexural waves on multilayer glass beams with different boundary conditions. In order to achieve reliable input mechanical data (Young's modulus and loss factor) the beams are characterized in free-free and clamped-clamped boundary conditions respectively.

Moreover, the diffuse field sound transmission loss of glass panels has been predicted through an analytical method for solid elastic layers. Results from the above-mentioned procedure have been compared with laboratory tests carried out according to ISO Standard 10140 series.
\end{abstract}

(C) 2015 The Authors. Published by Elsevier Ltd. This is an open access article under the CC BY-NC-ND license

(http://creativecommons.org/licenses/by-nc-nd/4.0/).

Peer-review under responsibility of the CENTRO CONGRESSI INTERNAZIONALE SRL

Keywords: Transmission Loss, Laminated glazing, PVB

* Corresponding author. Tel.: +39 041257 1485; fax: +39 0415311483.

E-mail address: pruggeri@iuav.it 


\section{Introduction}

Laminated glass is a sandwich-like type of safety glass system in which the glass panes hold together even when break as a consequence of a shock due to a viscoelastic interlayer that is typically made of polyvinyl butyral (PVB).

The procedure for measuring the loss factor and the equivalent bending rigidity in the specific case of laminated glass is described in ISO 16940 Standard [1]. The method makes use of bars of laminated glass with dimensions $25 \pm 2 \mathrm{~mm} \times 300 \pm 1 \mathrm{~mm}$, excited by a shaker connected to the middle of the test specimen. Many critical aspects of the standard method have emerged during the preparation of the test sample of this size. The fragility of the glass and the procedure of construction of laminated glazing itself, specifically the vacuum and autoclave processes, make it difficult, if not impossible, manufacturing test pieces of laminated glass with a thickness comparable with the glazing system commonly used in buildings.

The method proposed in this paper overcomes the limitations of the ISO 16940 Standard by carrying out measurements on larger test pieces, easier to realize.

\section{Description of the methodology}

In this paper, a simplified procedure based on both experimental tests on multilayer beams (with free-free and clamped-clamped boundary conditions) and numerical modelling for the calculation of the sound transmission loss of glazing multilayer systems are presented. The entire procedure can be summarised as follows:

- firstly, the resonance modes for flexural waves are determined for a suspended beam excited by a point source (as depicted in figure 1a), according to the specifications of ISO 6721-3 (Method B) [2]. For each resonance frequency obtained is calculate the flexural Young's modulus as follows:

$$
-\underline{1}^{2}{ }^{2}\left(\underline{\mathrm{f}_{\mathrm{ri}}}\right)^{2}[\mathrm{~Pa}]
$$

$\mathrm{E}_{\mathbf{f}}^{\prime}=\left[4 \mathrm{n}_{\left.\mathbf{f} 3 \mathrm{q}_{\mathrm{b}}\right]}\right] \quad \mathrm{k}_{\mathrm{i}}$

$\rho$ being the density $\left[\mathrm{kg} / \mathrm{m}^{3}\right], l[\mathrm{~m}]$ and $b[\mathrm{~m}]$ the length and width of the beams, respectively and $f_{\mathrm{ri}}$ the resonance frequencies [Hz]. $k_{\mathrm{i}}$ is a numerical factor [m ], which is: $k_{\mathrm{i}}=22,4$ for $i=1 ; k_{\mathrm{i}}=61.7$ for $\mathrm{i}=2$ and $\mathrm{k}_{\mathrm{i}}=(i+1 / 2) \pi$ for $i>2$.

- successively, it is necessary to determine the damping of the system $\eta$ to be simulated. The same beam is used free-free and clamped-clamped boundary conditions (as shown respectively in figure $1 \mathrm{a}$ and $1 \mathrm{~b}$ ) and the $1 / 3$ octave band loss factor is determined for both the boundary conditions by using the structural reverberation time method [3] which generally provides accurate results if the tested structure is characterised by small damping. $\eta$ value is calculated with equation 2 where $f$ is the frequency and $T_{\text {rev }}$ the structural reverberation time.

$$
5=\frac{2.2}{T_{\text {rer }} \cdot f}
$$

- finally, the sound transmission loss of the plate is calculated by using an analytical approach for a homogeneous and isotropic elastic solid having frequency dependent Young's modulus and a mean loss factor. Poisson's ratio is fixed to the value of homogeneous glass $(v=0.3)$ for all the simulations.

The transmission loss $R$ is calculated with equation 3 from the transmission coefficient $\tau(\theta)$ obtained from equation 4 [4]. In equation 3 the incidence angle $\theta$ is integrated from 0 to $75^{\circ}$ as described in [1].

$$
\mathrm{R}=10 \lg \left(\mathrm{f}_{\mathrm{f}}^{\mathrm{f}_{\mathrm{m}}^{8 \mathrm{lim}} \cos 8 \sin 8 \mathrm{~d} 8}\right)[\mathrm{dB}]
$$

$$
r(8)=\mid 1+\stackrel{f_{0} \quad c(8) \cos 8 \sin 8 d 8}{\left.\stackrel{m^{\prime} 2 n f \cos 8}{L}\left\{5\left({ }^{f}\right)^{2} \sin ^{4} 8+i\left[1-\left({ }^{f}\right)^{2} \sin ^{4} 8\right]\right\}\right|^{-2} \quad[-]}
$$

$$
\begin{array}{lll}
2 q_{0} c_{0} & f_{C} & f_{c}
\end{array}
$$


where $\eta$ is the composite plate loss factor (dimensionless); $m$ ' mass per unit area in $\mathrm{kg} / \mathrm{m}^{2} ; t$ is the thickness of the plate in meters; $\rho_{0}$ is the density of air, in $\mathrm{kg} / \mathrm{m}^{3} ; c_{0}$ is the speed of sound in air, in $\mathrm{m} / \mathrm{s} ; \theta$ is the angle of incidence; $f$ is the frequency.

The critical frequency is given by:

$$
\begin{array}{rr}
2 & \overline{\mathrm{mr}} \\
\underline{\mathrm{c}_{0}} & -
\end{array}
$$

$\mathrm{f}_{\mathrm{C}}={ }_{2 \mathrm{n}} \mathbf{J}_{\mathrm{B}}[\mathrm{Hz}]$

being $B$ is the plate bending stiffness per unit width, in Nm and depends by the Young's Modulus $E$ and the Poisson's Ratio v:

$$
\begin{aligned}
& \mathrm{B}=\mathrm{E} \\
& 12\left(1-w^{2}\right)
\end{aligned}
$$

\section{Measurement set-up and procedure}

Tested materials are summarized in Table 1 in which two types of PVB have been tested. Measurements of free suspended beams have been carried out on a specimen with a length of $1000 \mathrm{~mm}$ and a width of $100 \mathrm{~mm}$ by using an accelerometer and an impact hammer as depicted in Figure 1a. The impulse response has been acquired by using a NI USB 4431 acquisition device and has been post-processed by means of software developed in Labview ${ }^{\circledR}$. The frequency resolution has been fixed to $0.1 \mathrm{~Hz}$ for all the tests.

Table 1. Tested samples

\begin{tabular}{lccccccccc}
\hline ID of the sample & 8 & 44.1 & 44.2 & $44.2 \mathrm{ac}^{*}$ & 44.4 & 66.1 & 66.2 & $66.2 \mathrm{ac}^{*}$ & 66.4 \\
\hline Glass pane thickness [mm] & 8 & $4(\mathrm{x} 2)$ & $4(\mathrm{x} 2)$ & $4(\mathrm{x} 2)$ & $4(\mathrm{x} 2)$ & $6(\mathrm{x} 2)$ & $6(\mathrm{x} 2)$ & $6(\mathrm{x} 2)$ & $6(\mathrm{x} 2)$ \\
PVB thickness $[\mathrm{mm}]$ & - & 0.38 & $0.38(\mathrm{x} 2)$ & $0.38(\mathrm{x} 2)$ & $0.38(\mathrm{x} 4)$ & 0.38 & $0.38(\mathrm{x} 2)$ & $0.38(\mathrm{x} 2)^{*}$ & $0.38(\mathrm{x} 4)$ \\
Density $\left[\mathrm{kg} / \mathrm{m}^{3}\right]$ & 2440 & 2377 & 2320 & 2320 & 2220 & 2398 & 2358 & 2358 & 2285 \\
Thickness $[\mathrm{mm}]$ & 8.00 & 8.38 & 8.76 & 8.76 & 9.52 & 12.38 & 12.76 & 12.76 & 13.52 \\
\hline
\end{tabular}

*acoustic $P V B$

a

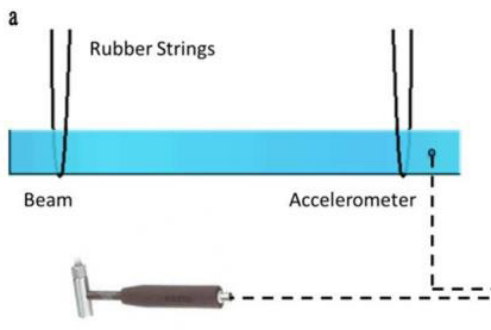

Impact Hammer

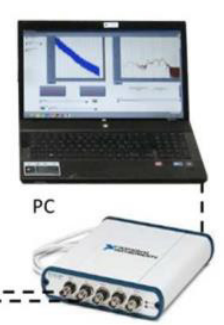

DAQ

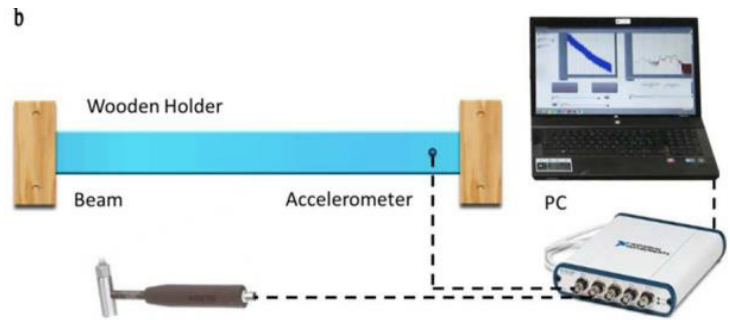

DAQ

Fig. 1. Sketch of the measurement apparatus: (a) free-free boundary conditions (b) clamped-clamped boundary conditions.

In order to determine the loss factor of the beams, two layouts has been used with two different boundary conditions: free-free and clamped-clamped. A sketch of the measurement set-up is shown in figure 1a and 1.b.

Finally, laboratory tests of sound transmission loss on a $1.48 \mathrm{~m} \times 1.23 \mathrm{~m}$ specimen have been carried out according to standards ISO 10140 parts 1, 2, 4 [5] in the EcamRiCert S.r.l. Laboratory. In order to avoid leakages a Perennator TX $2001 \mathrm{~S}$ sealant has been used between the wood frame and the plate as indicated in ISO 10140-1 annex D. Sound pressure levels in the source and receiving rooms have been measured by using L\&D 824 and the 
reverberation time by means of the interrupted noise method. During the measurement survey, the structural loss factor of the entire plate was also measured by using the structural reverberation time method using equation 2. A picture of the measurement set-up is depicted in Figure2.
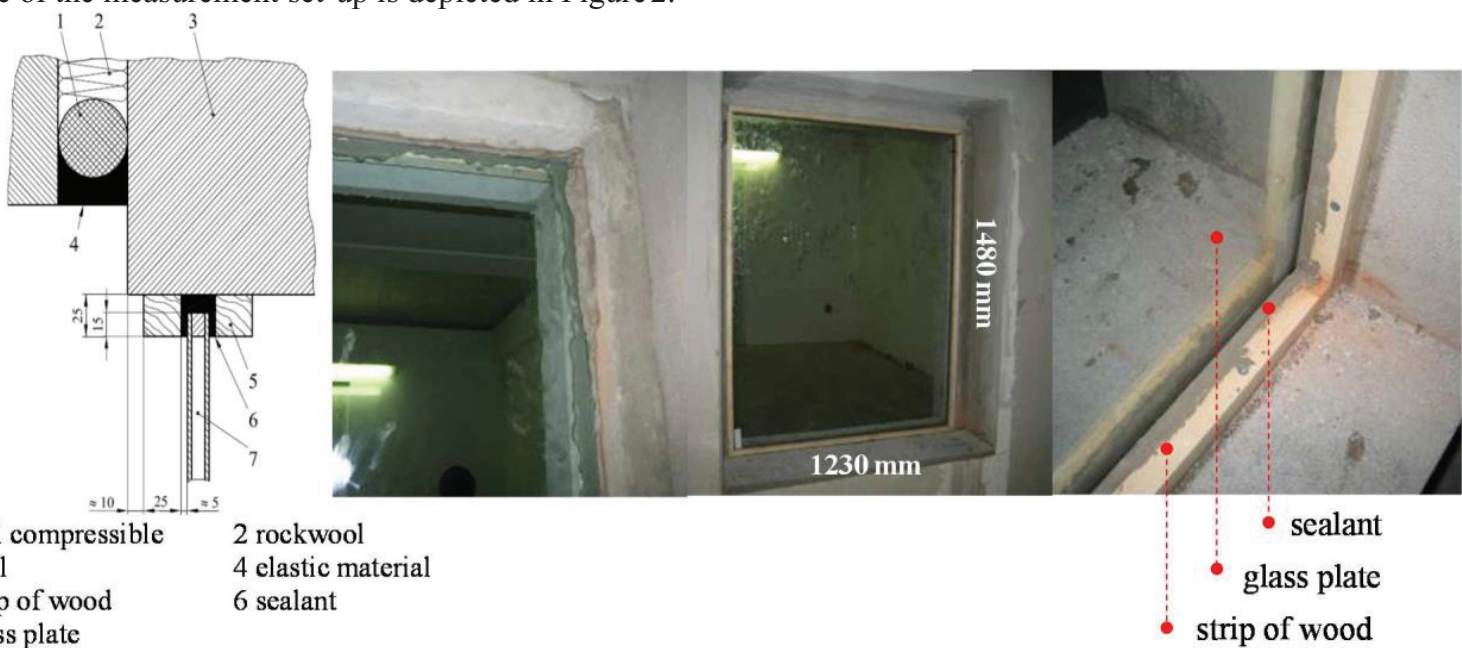

Fig. 2. Transmission loss laboratory measurement

\section{Results and discussions}

\subsection{Frequency-dependent Young's modulus}

Values of Young's modulus, $E$, as a function of the frequency are depicted in Figure 3 in the frequency range between $100 \mathrm{~Hz}$ and $5000 \mathrm{~Hz}$. The curves are obtained from interpolation of the discrete $E$ values obtained from the resonance frequencies with equation 1 . In the figure it is possible to observe a strong dependency of $E$ from the frequency.

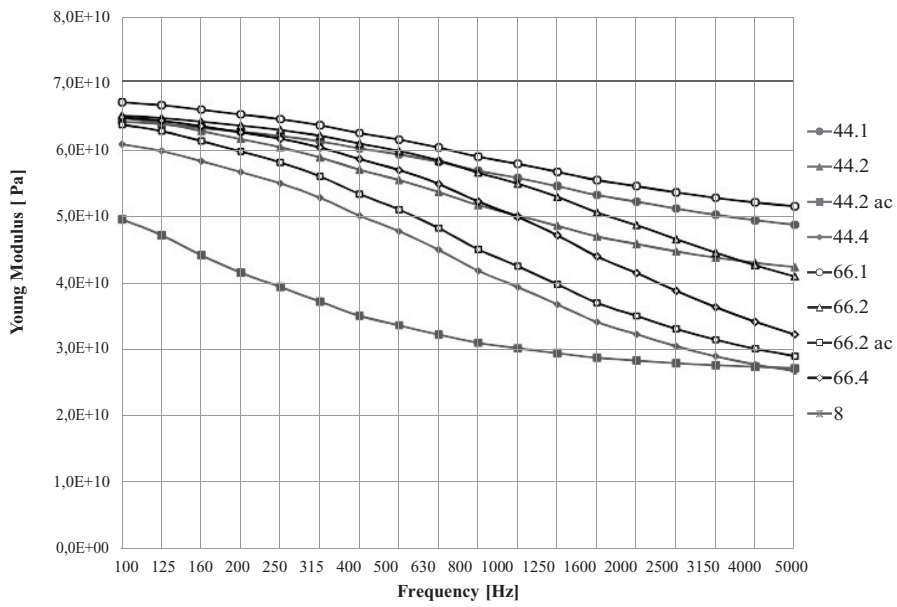

Fig. 3. Experimental values of frequency dependent Young modulus. 


\subsection{Damping}

From the results of the impulse measurements it is possible to observe that the damping is lower than 0.30 for all the tested clamped beams. Figure 6 represents a comparison between the mean loss factors for clamped and free suspended beams and the clamped plate. It is interesting to confirm that, apart from the cases when the acoustic PVB is used, damping from free suspended beams is too low if compared with the beams of the plate. In addition, the loss factors from the clamped beams quite satisfactorily represent the damping of the measured plates.
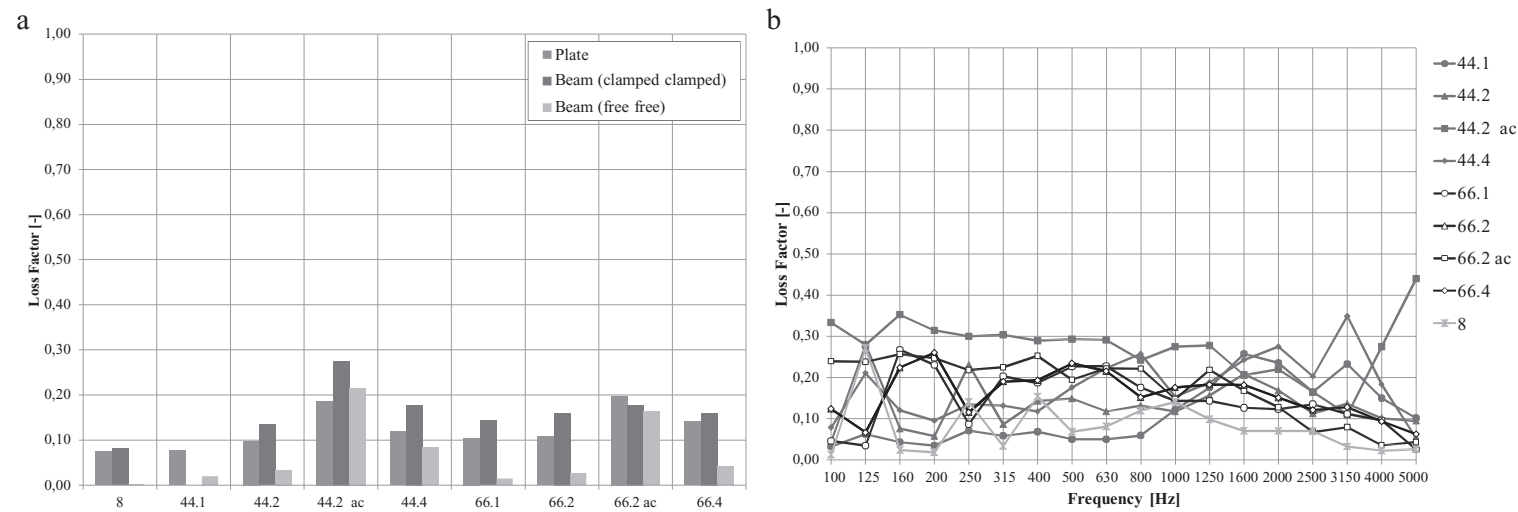

Fig. 4. Experimental values of loss factor; a) average values for different boundary conditions; b) frequency dependent values for clamped beams.

\subsection{Sound transmission loss}

Figure 5 depicts the comparison between the tests carried out according to ISO Standard 10140 series [5] and the model in terms of sound transmission loss for several tested plates. From the curves it is possible to observe that the analytical approach is able to correctly predict transmission loss and in particular the critical frequency of the plates. In addition, the estimated loss factors are able to simulate the damping at the critical frequency with accuracy. In the same figure are compared many analytical curves calculated using Young modulus and Dynamic Stiffness obtained in different configurations:

- 44.2_A and 66.4_A are calculated with Young modulus of the monolithic glazing (frequency independent) and loss factor averaged in frequency domain measured from the beam with clamped-clamped boundary conditions;

- 44.2_ B and 66.4_B are calculated with frequency dependent Young modulus and loss factor averaged in frequency domain measured from the beam with clamped-clamped boundary conditions;

- 44.2_ C and 66.4_C are calculated with frequency dependent Young modulus and loss factor averaged in frequency domain measured from the beam in free-free boundary conditions;

- 44.2_ D and 66.4_D are calculated with frequency dependent Young modulus and loss factor averaged in frequency domain measured from the glass plate.

All the above listed analytical curves have the same values below the critical frequency. Above this frequency they have a different trend that depends from the loss factor and the Young modulus values.

In fact the sound transmission loss calculated by using the loss factor by free-free beams data underestimate the transmission loss values; the transmission loss calculated with the non-frequency dependent young modulus does not match the critical frequency. Both the curves that uses the loss factor measured from the plate and the clamped beam, well match the experimental values.

Some discrepancies appear in the lower frequencies. This is due by the analytical approach that does not consider the finite size of the plate. 

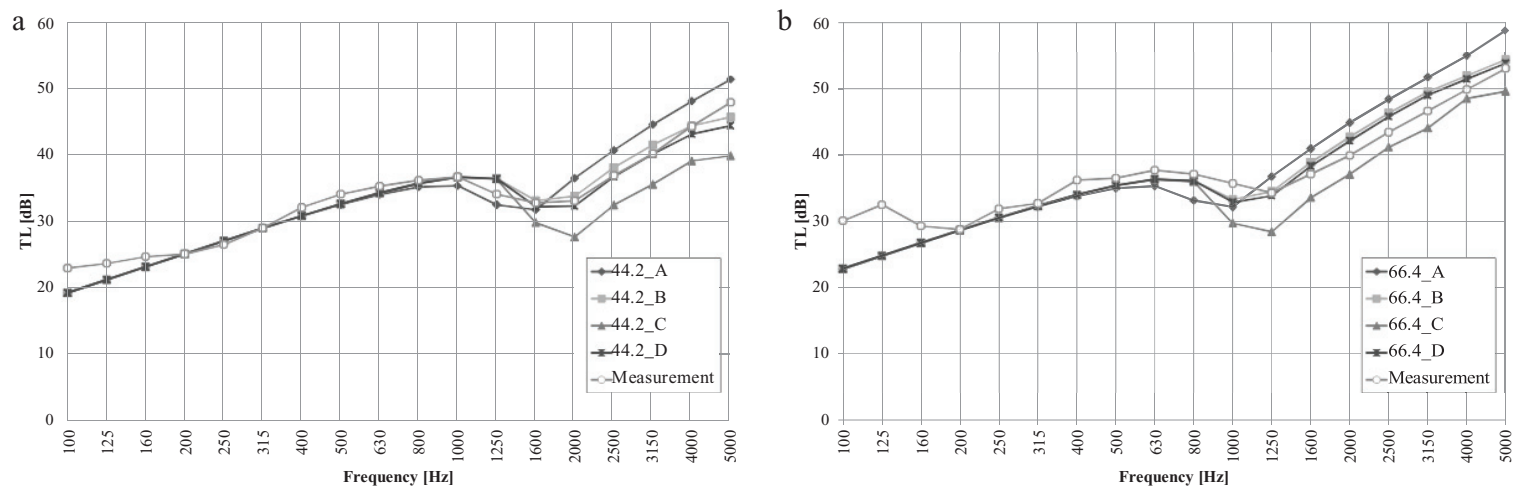

Fig. 5. Comparison between Measured and theoretical Transmission loss: (1) 44.2 glazing plate, (2) 66.4 glazing plate.

\section{Concluding remarks}

In this work an analytical approach has been presented to predict the sound transmission loss of glazing. The elements used for the analysis were both homogeneous and laminated glass plates. Using an impact hammer and an accelerometer, connected to a special acquisition system, the resonance frequencies of small samples of glass and laminated glass were measured, consisting of $100 \mathrm{~mm} \times 1000 \mathrm{~mm}$ beams with free edge constraints. From the resonance frequencies it was possible to measure the flexural Young's modulus as specified by ISO 6721-3 Standard, with the hypothesis that the glass plates are assumed to move in phase at high frequencies. Within this frequency range the bending stiffness for the entire beam is equal to the sum of the bending stiffness of the glass plate. In order to determine the loss factor to be used in the simulations, the structural reverberation time has also been measured in three structural conditions, (i) free-free constraint beam (dimensions $100 \mathrm{~mm}$ x $1000 \mathrm{~mm}$ ); (ii) clamped-clamped constraint beam (dimensions $100 \mathrm{~mm}$ x $1000 \mathrm{~mm}$ ); and (iii) constraint plate in the laboratory (dimension $1230 \mathrm{~mm} \times 1480 \mathrm{~mm}$ ). Finally, the transmission loss of the glazing systems was measured in the laboratory according to ISO 10140 Standard. The modified measuring apparatus, with clamped-clamped constraints of the beam, has made a significant improvement in results near the coincidence frequency, as the loss factor measured in these conditions appears to be comparable to that of the plate used for the transmission loss measurement in the laboratory.

\section{Acknowledge}

Authors want to thank dott. Mario Checchin (Checchin Vetri e Cristalli S.r.1.) who provided all the glass samples used for testing. and EcamRiCert S.r.l. laboratory for the support in the measurement of transmission loss of the glass panes.

\section{References}

[1] ISO 16940: 2008, Glass in building - Glazing and airborne sound insulation - Measurement of the mechanical impedance of laminated glass.

[2] ISO 6721-3:1994, Plastics - Determination of dynamic mechanical properties - Part 3: Flexural vibration-Resonance-curve method, (International Organization for Standardization, Geneva 1994).

[3] F. Jacobsen, J. H. Rindel, Time reversed decay measurements, Journal of Sound and Vibration, Volume 117, Issue 1, pp 187-190 (1987).

[4] I.L. Vér, L.L. Beranek, Noise and vibration control engineering, John Wiley \& Sons, Inc., Hoboken, New Jersey, (2006).

[5] ISO 10140-2:2010, Acoustics - Laboratory measurement of sound insulation of building elements. Part 2: Measurement of airborne sound insulation (International Organization for Standardization, Geneva 2010).

[6] P. Bonfiglio, F. Pompoli, A.T. Peplow, A.C. Nilsson, Aspects of computational vibration transmission for sandwich panels, Journal of Sound and Vibration, Volume 303, Issues 3-5, 780-797 (2007) 